\title{
The Study of Social Media Alienation in the Digitized World
}

\author{
${ }^{1}$ The University Of Sheffield \\ ${ }^{2} X i$ 'an Jiaotong-liverpool University \\ *Corresponding author. Email: kexin.gao19@student.xjtlu.edu.cn \\ ${ }^{\dagger}$ These authors contributed equally.
}

Haochen $\mathrm{Bai}^{1, \dagger}$, Kexin $\mathrm{Gao}^{2, \dagger, *}$

\begin{abstract}
As the digitization of society progressed, the connection between lifestyle and social media use has been strengthened. Such advancement has been designed to simplify human interaction while providing its users with diversified functions like entertainment, sharing, community, even shopping. Although the popularity of social media has been a great benefit for information flew and lifestyle inspiration, some drawbacks of such radical change should be argued from a societal perspective. Social media itself is regarded as a technical improvement progressed to provide its users with better communication and a more enjoyable online life. However, it has enslaved its users psychologically, and the users become victims of the digital product instead of its controller. Such conflict, which is on the opposite side of the initial purpose when it was designed, can be defined as alienation. The essay has driven multiple academic resources to offer an illustration of the social media alienation phenomenal. Meanwhile, applying several second-hand literature from an outstanding scholar in a related area to support its argument. It explores the phenomena of social media alienation then tries to develop possible reasons behind the alienation. The discussion and summary in the final part concludes with the inspiration people can get from the battle against alienation and some possible solution to the addiction. The research result is expected to inspire digital society: the importance of managing social media use must be stressed. People need to use any possible and decent strategy to enjoy their online interaction instead of being controlled even ruined by social media. The significance can be observed from the following parts: it draws the general definition of alienation and social media with their discussion individually to introduce the key point of social media alienation. It focuses on the relationship between social media and its user to discuss the conflict in the alienation process, with each argument supported by related literature. It looks for the phenomena meanwhile puts effort into analyzing the reason behind it. In the end, it provides inspiration and possible strategies for people struggling with social media alienation.
\end{abstract}

Keywords: "social media”, “alienation”, “user”, "phenomena”, “reason”

\section{INTRODUCTION}

The use of social media on a digital platform is on a rapid increase. The popularization of social media has led to the change of human lifestyle. Business can benefit a lot from using the social network in building a connection with the customer. Hence, there is a better chance for enterprise to extend their business and strengthen their relationship with customers. Companies would turn to work more on the collaboration with the digital platform to optimize their advertisement and personalized service on social media to drive more profit from the users [1]. As for users themselves, social media is playing a significant role in leading people's behavior change. Social media can be educational in the process of people forming their identity, providing them a sense of belonging and helping them build self-esteem. It connects people around the world and updates the latest news globally [2]. However, the overuse of social media is also problematic. Studies show a positive correlation between mental health issues and digital media addiction [1] People with a poor mental health condition and low self-value turn to develop an over-rely on the use of social media with regard it as compensation for daily social interaction [3]. In addition, such groups of people are more likely to use social media as their emotion management tool. However, when they are not satisfied, their minds turn to get worse [4]. Such unexpected influence on user behavior which is on the opposite side 
of its intention in its design process, is normally regarded as "alienation". Social media is created to help with communication and better understanding. However, the issues that come with its benefit can be a disaster to human mental health and real-life interaction. Such kind of conflict can be widely observed in the modern digital society. Hence, it is important to conduct further research about the influence of social media alienation on its users. This essay will reflect on some former literature related to social media influence, alienation, and the alienation effect on social media users to evaluate its strength and flaws. Based on the evaluation of previous academic resources, it then tries to describe the possible form of social media alienation, following by the discussion about the reason behind it, ends up with the evaluation of such phenomena and their potential influence on the digital society. At the same time, they are coming up with a reasonable solution to the potential harm.

\section{LITERATURE REVIEW}

The Research topic around the influence of social media on digital society has always been popular, and alienation is also a sociological phenomenon that researchers focus on. However, the research on social media alienation is a relatively new topic in academic circles. In recent years, scholars have focused on exploring the benefit of social media and the side effects it brings at the same time. Therefore, more academic resources are available to support the research of social media alienation. Moreover, such an issue is not a single study in media but involves analyzing and thinking in sociology, psychology, culture, communication, etc.

Although rich academic resources have been involved in this study, they can be put into three categories: The first division can define social media's role. Elizabeth and Jennifer regard social media influence as an application of psychology. Hence, both communication and social psychology should be analyzed the media influence in the time of crisis. Unlike the research perspective, Elizabeth and Jennifer chose, Boulianne[5] focus on the role social media plays in civic and political life, emphasizing its power in promoting political expression but less in the use of information, and they all rely on the political context. On the other hand, Liu and Li try to discuss the influence of social media from a societal and cultural point [6]. They claimed social media provide users with a better chance to communicate. However, the misuse of the platform also accelerates polarization and violence.

Besides the definition of social media characteristics, another category is regarded as the interpretation of alienation. Yang [7]illustrated Marx's observation of Men in their activities, regarded other material as tools, and yet they became tools and played by other forces. Marx regards such kind of relationship as a mutual interaction between humans and the environment.
Environment shapes human, and human also plays a part in the environmental change. Inspired by Marx's understanding of alienation, $\mathrm{Hu}$ [8] comes up with the concept of alienation of consumer culture. Max mentioned the purpose of people's labor is instead not to meet their own production needs but become the slavery of labor itself. However, in modern consumer culture, the symbolic interpretation of consumption is achieved through marketing strategies that paralyze the original concept of production and give it new symbolic meaning. Such kinds of symbolic fiction and simulation have led to the obsessive pursuit of the meaning behind symbols. In this process, people gradually become slaves of symbols.

When applying the alienation theory to social media study, the related academic resources can be available to study social media alienation. Wu [9] defines such kind of alienation as "extreme panic". They are alienated from the role of actively consuming but become controlled and enslaved by media. Hence, how to keep an independent spirit in the virtual world is the topic of modern society. In his analysis, the alienation of social media is the result of multiple factors. Technology has been improved to meet people's demands, but it gradually replaces people's rational thinking and makes them lack the motivation to take action. At the same time, the entertaining nature of social media gives people an illusion of happiness, and consumerism has been magnified, resulting in a waste of resources. Zhang and $\mathrm{Yi}$ use Marxist theory in their explanation by focusing on all objects involved in social media alienation. Alienation is related to the intention of taking control of resources but escaping from responsibilities. At the same time, the network crisis is caused by the collapse of the relationship between people and the network environment. Hence, users' position is changed from dominance to passively under control.

The current academic resources focus on social media alienation on consumption and entertainment, meanwhile emphasizing the subversion of subject and object. However, social media influence on users needs to be further studied. Alienation emphasizes the relationship change between subject and object. From this perspective, changes in users' thinking ability, time management skills, involvement in discourse, and supervision are other issues that need to be further researched.

\section{THE EXPRESSION FORM OF INTERNET ALIENATION PHENOMENON}

\subsection{Less Independent Thinking}

The convenience brought by smartphones has prompted users' to rely on media. Media itself has been regarded to provide as much information as the users ask for [10]. In addition, it is also related to how people 
entertain themselves and relieve pressure. Hence, people have highly relied on media to get satisfied.

As the alienation of social media has been more severe, social media has gradually manipulated human life. Such kind of manipulation can be observed on various occasions. As soon as people get the chance, they can't help look through all kinds of information and update on the phone. People would rather chat online than talking with friends who sit exactly opposite chairs. Over relying on social media leads to more activity in the virtual world but less interaction in real life [11].

For example, people will get nervous if they keep away from their phones for a while because they don't want to miss any chance to see any new post or message on social media. people's demand for self-expression and admission from others has been controlled by social media [12].

The reasons behind people's dependence on social media can be attributed to the need for both solitude and social life. People naturally possess the emotional need to get praise, approval, and respect from the outside world. Meanwhile, to seek a higher level of mental appeal, people turn to look for a space of solitude to know themselves better and reflect on their behavior. However , since most people cannot manage their time properly, they are more likely to trap in fear and insecurity when alone. Hence, it provides social media with a great chance of getting into people's life. People can share feelings and information with others. The sense of belonging and satisfaction makes people get addicted to it. In the virtual world, people can display a certain image and share the better part of themselves. They enjoy the feeling of getting recognized. In contrast, people in real life can be more likely to avoid human interaction due to the high pressure of daily tasks and work. Hence, social media has been used as a way to relieve pressure and tension [10].

Through social media, people can drive happiness from solitude and social life at the same time. Such kind of tool satisfy human's emotional feeling in an unprecedented efficient way. People get trapped in the use of social media and find cannot get rid of it anymore.

\subsection{Users' ability To Distinguish Between Different Information Continues To Fall}

The ability to distinguish between all kinds of information has defined how we can critically take in the messages from mass media, knowing the benefits and drawbacks [13]. For instance, people turn to follow the trend before knowing the whole picture regarding all kinds of fake news and scandals on social media. Hence, in many cases, it can lead to tragedy. The open and free network environment gives social media the chance to duplicate. All kinds of individuals can get access to the social media industry without a fair standard. They pay more attention to getting people to click more instead of spreading the real story. Hence, the public cannot form the correct value and just follow the trend without deep consideration. In this case, people will take information from all sources, leading to the potential of harm. In addition, the pictorial and simplified version of information has accelerated irrational behavior. At the same time, society does not provide a well-established supervision system for online activity. Since people are not that sensitive to related content, the reaction only stays at a moral stage.

\subsection{Lose Control of Own Life}

Managing one's own life indicates the ability to cultivate in-depth thinking, analysis, and judgment of value. The capability of solving own problems without any kind of external tools has been considered to have control of own life [14]. However, people are connected with the network has been greatly strengthened nowadays. Under the influence of digitization, people's main focus is on speed and efficiency. Gradually, the solution to the problem has been replaced by the search engine.

In addition, people fail to manage their time, especially when they receive updates from their phones. The curiosity in their mind drives people to look through various information. The openness of the internet has contributed a huge part to chaotic life, users who do not put in much consideration may post emotional content with the help of free speech. Without much reflection on moral principles, people fail to live life the way they intend to. In the process of content dissemination.

The algorithm also plays a vital role in recommending personalized posts to users. Hence, people will rely more on the content they passively get instead of searching for it initially. With much more distraction, people can find it hard to drive the knowledge they need from the online environment but get more annoyed by losing control of real-life and interaction.

\subsection{Collective consciousness of individual consciousness}

Applying Le Bon's theory of crowd mind, people can lose their personality when they try so much to get involved in the bigger group. When the community forms, the emotional expression will be amplified, and finally leads to impulsion, fanaticism, and credulity. Hence, problems can't be settled properly. When individuals are independent, they tend to check whether their behavior is appropriate and suppress their instincts. However, when they act as a group, they feel less guilty since the individual is not the only one to blame. Hence, fewer responsibilities will be taken with moral pressure falling. 
Such cases can never be rare. During the French Revolution of the 18th century, many of the commissioners in the parliament are also mild citizens. However, once they get hold of the power, they collectively put forward barbaric and self-interested proposals, which eventually leads to the point of sending themselves to the guillotine [15].

When public psychology has been put into the research, it will be easy to find people feel certain pressure when they stay in the community. To get along well with the peers, they turn to adopt the characteristics. Unconsciousness will gradually erode their judgment, lead to fanatic. At the same time, the influence of celebrities on social media who have a certain group of followers can be exaggerated. Hence, followers become believers without their judgment and value [16]. A certain post from a certain person can manipulate and inflame the masses' emotions with precision and effectiveness, which finally leads to the disorientation of the masses.

\section{THE ANALYSIS OF THE CAUSE OF ALIENATION}

Since the phenomenon of social media alienation has been very clear, it is very necessary to explore the reasons behind it. Any kind of social phenomenon cannot be simply attributed to the result of a single factor. Hence, it is important to find the most prominent contradiction in the phenomenon of alienation. As the digitization of human social processes, the quantity and speed of information have become the most concerned questions of social media users. Information has become more and more dependent on media so that all information has to be medialized for better dissemination. Social media constantly update its service through technological upgrading to drive more attention from users and provide information that interests users. The media is called the most important source for people to get information. Hence, studying its causes will help us find out the mechanism of alienation and explore a possible solution to the issue.

\subsection{Worship Of Technology}

Under the wide popularity of social media, the relationship between technology and users has been greatly changed. While people enjoy the benefit of technology development, people turn to regard it as the key to every problem. Hence, Technology worship can be defined as an ideological preference that people get pleasure from the experience and imagination of technology. In the era of continuous development and perfection of technology, people rely more and more on technology since they live with a lack of security. They always believe that the development of science and technology can solve all problems. Subconsciously, people now have full trust and admiration for technology [17]. Because technology not only pleases people but also helps to deal with the fear caused by insecurity.

The Internet and media platforms seem to be completely tied to people's lives. People can use mobile phones to communicate with anyone, even if they are literally sitting opposite them. The leisure activities are also moving to social media, where people can play online games with their friends from Facebook and what's app. Book order on UberEats when being hungry, subscribe to Netflix when getting bored, and Amazon when shopping. In a word, people no longer have to go out. In such a case, real-life interpersonal communication is redundant.

\subsection{Consumerism}

Consumerism is a societal phenomenon generated by people based on their habits, cognition, and consumption behavior. It guides people's behavior patterns and values in life [18] and regulates people's actions in terms of consumption and their principles, thoughts, desires, emotions, and practices.

However, as people spend more time on social media, it also tends to promote more advertising and drive benefit. All kinds of products recommendation can interfere with people's choices and judgments. This can be problematic since people no longer choose based on their preference but recommendation. Besides passive consumption, irrational consumption is another issue: social media, to drive its own commercial revenue, constantly spread the views of consumerism culture to the public by taking advantage of the emerging consumerism culture and strengthen people's recognition of consumerism and their desire for consumption [18]. Under the guidance of such behavior, people's thinking and cognition will gradually change and often commit Impulsive consumption. The mutual penetration and influence of media and consumerism finally lead to their alienation [18].

The emergence and alienation of consumerism have brought great changes to people's lives, and leisure and entertainment have become the main content of people's consumption. People began to consume for spiritual satisfaction rather than pure food and clothing.

\section{CONCLUSION}

This article draws the following conclusions through the discussion and analysis of social media alienating people:

1. The rapid development of social media makes individuals more and more subject to others and alienates them specifically in the following aspects: their dependence on the media continues to increase; their ability to discern information continuously weakens; 
their ability to control their own lives continues to weaken; and when they are in a group, they become more emotional, less intelligent, and less dissenting.

2. This article further analyzes the causes of social media alienation, mainly manifested in two aspects: technology worship and consumerism alienation. They take advantage of people's sense of insecurity and innate desire for consumption to control people's minds, thus manipulating people's behavior.

However, this article has the following shortcomings in the process of doing research: when collecting data, the paper mainly focuses on second-hand data, which have certain defects such as being not specific and detailed enough, consequently restricting the specific analysis and demonstration process in this article and influencing the final conclusion. For example, references, which do not have enough examples and data to support conclusions, are often discussed only theoretically.

Despite the above shortcomings, the article still has the following value and significance:

1. To begin with, the topic of this article is initiative, for there are not many discussions and thorough conclusions on social media are alienating people by predecessors. Secondly, when we analyzed the reasons behind the phenomenon, we, rather than just confined to the theory of alienation, did some more fundamental theoretical analysis.

2. This article demonstrates how social media alienates people from the relationship between the audience and the media, making this article richer and more complete in terms of its theoretical significance.

3. We dissect the causes of social media alienating individuals by analyzing its ways of alienation so that some enlightenment can be provided for people to avoid being alienated by social media in real life. After people read this article to figure out the truth behind social media, they can recall the content of this article to remind themselves that social media should not control them. When they find themselves indulging in social media uncontrollably in their daily lives, they can get rid of social media's alienation and lead a better life.

\section{REFERENCES}

[1] https://www.brafton.co.uk/blog/social-media/12-ben -efits-of-social-media-and-all-the-ways-it-canimpact-your-business-for-good/

[2]https://www.techmaish.com/advantages-and-disadvantages-of-social-media-for-society/

[3] Caplan, S. E. (2010). Theory and measurement of generalized problematic Internet use: A two-step approach. Computers in Human Behavior, 26, 10891097.https://doi.org/10.1016/j.chb.2010
.03.012Heidelberg, 2007, pp. 220 - 270. DOI: https://doi.org/10.1007/978-3-540-72522-0_6

[4] Coen, Sharon. "Media Effects and Society." Social Psychological Review, vol. 19, no. 1, Summer 2017, pp. 36-37. EBSCOhost, search.ebscohost.com/login.aspx?direct=true $\& d b=$ asn $\& A N=122917191 \&$ site $=$ eds-live $\&$ scope $=$ site .

[5] Boulianne, Shelley. "Revolution in the Making? Social Media Effects across the Globe." Information, Communication \& Society, vol. 22, no. 1, Jan. 2019, pp. 39 - 54. EBSCOhost, doi:10.1080/1369118X.2017.1353641.

[6] Chanjun, Liu. Seeking the Fusion of Multiple Information Inputs and Rational Output - - The Public Social Media Use and Their Influence on Social Governance." Journal of Intelligence, vol. 38, no. 5, Jan. 2019, pp. 130 - 141. EBSCOhost, doi:10.3969/j.issn.1002-1965.2019.05.019.

[7] Qi, Yang. "Alienation, liberation, and Civilization -Also on the value dimension of Marx and Engels'" natural liberation. "Journal of Shandong Agricultural University (Social Science Edition), vol. 21, no. 2, Jan. 2019, pp. 108 - 112. EBSCOhost, search.ebscohost.com/login.aspx?direct=true $\& \mathrm{db}=$ edscoj\&AN=edscoj.sdnydxxb.shkxb201902017\&si te $=$ eds-live $\&$ scope $=$ site.

[8] Min, Hu. Survey and Guidance of Consumption Alienation From the Visual Threshold of a New Media." Future and Development, vol. 43, no. 5, Jan. 2019, pp. 46 - 77. EBSCOhost, doi:10.3969/j.issn.1003-0166.2019.05.009

[9] Xianghua, Wu. "The alienation of social media to people in the new media environment." Youth Journalist, no. 29, Jan. 2016, pp. 27 28. EBSCOhost, search.ebscohost.com/login.aspx?direct=true $\& d b=$ edscoj\&AN=edscoj.qnjz201629016\&site=edslive $\&$ scope $=$ site.

[10] Haoyu, Chen. "Coexistence and solitude: an analysis of social media dependence in the era of urban network survival." New Media Research, vol. 4, no. 19, Jan. 2018, pp. 115 - 123. EBSCOhost, doi:10.3969/j.issn.1671-7597.2018.19.050.

[11] Zhensheng, Liu. "Social media dependence and media demand: a case study of College Students' microblog dependence."Journalistic University, no. 1, Jan. 2013, pp. 119 - 129. EBSCOhost, search.ebscohost.com.ez.xjtlu.edu.cn/login.aspx?di rect $=$ true $\& d b=$ edscoj\&AN=edscoj. $x w d x 20130101$ $9 \&$ site $=$ eds-live $\&$ scope $=$ site . 
[12] Sining, Cao. "From the perspective of" taking photos before dinner "to see the alienation of social media to people."Radio \& TV Journal, no. 7, Jan. 2016, pp. 158 - 159. EBSCOhost, search.ebscohost.com.ez.xjtlu.edu.cn/login.aspx?di rect $=$ true $\& d b=$ edscoj\&AN=edscoj.st $201607096 \&$ s ite $=$ eds-live $\&$ scope $=$ site.

[13] Qianqian, Wei., \& Yinghui, Wang. "Research on the current situation of College Students' network information discrimination ability."Modern Business Trade Industry, no. 23, Jan. 2012, pp. 197 - 198. EBSCOhost, search. ebscohost.com.ez.xjtlu.edu.cn/login.aspx?direct=tr $\mathrm{ue} \& \mathrm{db}=$ edscoj$\& A N=$ edscoj. $x d s m g y 201223111 \&$ si te $=$ eds-live $\&$ scope $=$ site.

[14] Zhonghui, Ren. "Liberation or enslavement: an eternal topic between Internet and netizens."Editors' Friend, no. 10, Jan. 2014, pp. 52 - 54. EBSCOhost, search.ebscohost.com.ez.xjtlu.edu.cn/login.aspx?di rect=true $\& \mathrm{db}=$ edscoj $\& \mathrm{AN}=$ edscoj.bianjzy 2014100 $14 \&$ site $=$ eds-live $\&$ scope $=$ site.

[15] Liang, Xu., \& Chunhua, Zhou. "Analysis of the influence of mob group psychology on the evolution of Internet public opinion."Journal of Seeking Knowledge Guide, no. 24, Jan. 2018, pp. 22 25. EBSCOhost, doi:10.3969/j.issn.2095-624X. 2018.24.007.

[16] Jieyang, Huang. "A study of mass psychology in modern information society triggered by mob."Speed Reading, no. 8, Jan. 2019, p. 39. EBSCOhost,

search.ebscohost.com.ez.xjtlu.edu.cn/login.aspx?di rect $=$ true $\& d b=$ edscoj\&AN=edscoj.sd.xx20190803 $6 \&$ site $=$ eds-live $\&$ scope $=$ site.

[17] Peiqing, Xu. 'Technology Salvation' of the Future World:Brief Analysis of Technology Worship in 2012. " JOURNAL OF NINGBO RADIO \& TV UNIVERSITY, vol. 08, no. 2, Jan. 2010, pp. $97 \quad-\quad$ 101. EBSCOhost, doi:10.3969/j.issn.1672-3724.2010.02.031.

[18] Mengxuan, "Lin. The tendency of news consumerism in the new media era" Today's Mass Media, no. 6, Apr. 2021, pp. 31-33. 